\title{
Antigenicity and immunogenicity of allogeneic retinal transplants
}

\author{
Natalie G. Anosova, Ben Illigens, Florence Boisgérault, Eugenia V. Fedoseyeva, \\ Michael J. Young, and Gilles Benichou \\ Cellular and Molecular Immunology Laboratory, Schepens Eye Research Institute, \\ Department of Ophthalmology, Harvard Medical School, Boston, Massachusetts, USA \\ Address correspondence to: Gilles Benichou, Cellular and Molecular Immunology Laboratory, Schepens Eye Research \\ Institute, Department of Ophthalmology, Harvard Medical School, 20 Staniford Street, Boston, Massachusetts 02114, USA. \\ Phone: (617) 912-7465; Fax: (617) 912-0129; E-mail: gilles@vision.eri.harvard.edu.
}

Received for publication January 11, 2001, and accepted in revised form September 10, 2001.

\begin{abstract}
The transplantation of neuronal cells and tissues represents a promising approach for the treatment of incurable neurodegenerative diseases. Indeed, it has been reported recently that retinal transplantation can rescue photoreceptor cells and delay age-related changes in various retinal layers in rodents. However, retinal grafts deteriorate progressively after placement in recipients' eyes. Here we investigated whether a host's immune response elicited toward the graft contributes to its deterioration. Using an ELISA spot assay, we measured $T$ cell responses to retinal tissues placed in the vitreous cavity of syngeneic and allogeneic mice. We found that allogeneic retinas induced potent alloimmune responses mediated by $T$ cells secreting type 1 cytokines (IFN- $\gamma$ and IL-2). No response was found in mice engrafted with syngeneic retinas. In addition, all syngeneic retinal grafts displayed no signs of tissue damage (at 55 days), while the majority of allogeneic retinas deteriorated as early as 12 days after placement. Next, we showed that anti-donor responses occurred within two phenotypically and functionally distinct $\mathrm{T}$ cell subsets: $\mathrm{CD}^{+} \mathrm{T}$ cells secreting IL-2 and $\mathrm{CD}^{+} \mathrm{T}$ cells producing IFN- $\gamma$. Importantly, $\mathrm{CD}^{+} \mathrm{T}$ cells were necessary and sufficient to cause graft deterioration, while $\mathrm{CD}^{+} \mathrm{T}$ cells did not contribute to this process.
\end{abstract}

J. Clin. Invest. 108:1175-1183 (2001). DOI:10.1172/JCI200112204.

\section{Introduction}

Since the early 1970 s, different solid organ transplants, including kidney and liver, have been performed in humans with a reasonable rate of success. Some recent studies suggest that successful transplantation of neuronal cells and tissues could also be achieved. There are still, however, formidable barriers to accomplishment of this type of transplantation. First, it is not known whether transplanted neural cells can survive for extended periods of time in recipients and form proper connections with host cells, thereby restoring functional networks. Second, whether these transplants are recognized by the host's immune system and whether their integrity is affected by the subsequent immune response remains open to question.

Retinal transplantation represents a promising approach for restoring sight to patients with diseaseand age-related irreparable damage to the retina (1-9). Various techniques have been developed to transplant cultured cells onto Bruch's membrane, including open sky as well as transvitreal and transchoroidal surgeries $(4,8)$. A number of groups have reported that normal retinal pigment epithelium (RPE) cells implanted into the subretinal space of the eye of RCS rats can rescue photoreceptor cells undergoing degeneration $(7,10)$. In addition, transplantation of RPE in rat eyes was shown to delay age-related changes in various retinal layers and represents a possible approach to deal with cell death in aging retina (11). Both RPE and neural retina cell transplants are currently being developed for patients with age-related macular degeneration and other neurodegenerative retinal diseases (9). Taken together, these seminal studies suggest that if successful transplantation of retinal tissues could be achieved, it would have broad therapeutic applications. However, enthusiasm for this type of transplantation has diminished because all orthotopic retinal transplants systematically deteriorate after transplantation. While the mechanism underlying such retinal graft degeneration is unknown, it has been assumed that this phenomenon is not initiated and/or caused by the host's immune system. This assumption was based upon the immune-privileged nature of the eye and the low level of MHC expression on retinal tissue $(12,13)$. In turn, this phenomenon was attributed to the inability of these grafts to make axonal/dendritic connections rather than to immune-mediated rejection, a conclusion that had, however, never been substantiated by a thorough immunological analysis.

Some evidence has been provided indicating that, under defined circumstances, retinal tissues placed in the eye of a genetically disparate recipient are immunogenic (12-17). First, Jiang and Streilein reported that neonatal neuronal retinal grafts survived over 100 days after placement in the eye's anterior chamber of syngeneic mice. In contrast, similar transplants displayed 
deterioration 35 days after transplantation when placed in histoincompatible recipients (12-17). This suggested that immune recognition of some donor antigens of the graft was responsible for the rapid deterioration of retinal grafts in allogeneic hosts. Similar findings were reported with retinal grafts placed in both subretinal space and vitreous cavity of the eye. Moreover, it was observed that both syngeneic and allogeneic retinal transplants survived comparably well over 100 days in SCID mice devoid of an immune system $(12,13,17)$. Taken together, this suggested that allogeneic retinal tissues, although they had been placed in a known immune-privileged compartment of the eye, evoked an immune response, which lead to accelerated graft deterioration.

Here, we used a highly sensitive ELISA spot assay in order to investigate $\mathrm{T}$ cell responses in mice transplanted in the vitreous cavity of the eye with retinas from fully allogeneic donors. We detected potent antidonor $\mathrm{T}$ cell-mediated responses in the draining lymph nodes and spleen of recipient mice. Both $\mathrm{CD}^{+}$and $\mathrm{CD}^{+} \mathrm{T}$ cells were activated, although each $\mathrm{T}$ cell subset displayed distinct lymphokine patterns. Induction of alloreactive $\mathrm{T}$ cell response was initiated by recipient $\mathrm{CD}^{+} \mathrm{T}$ cells recognizing donor MHC class II in a direct fashion, a result strongly suggesting the presence in the transplanted retina of $\mathrm{MHC}$ class $\mathrm{II}^{+}$cells serving as passenger leukocytes. The implications of these findings in transplantation of retinal and other neuronal tissues are discussed.

\section{Methods}

Mice. Female BALB/c (H-2 $\left.2^{\mathrm{d}}\right)$ mice, C57BL/6 $\left(\mathrm{H}-2^{\mathrm{b}}\right)$ mice, and all MHC-deficient (MHC class $\mathrm{II}^{-/}$) and MHC class I- $\left(\beta_{2} \mathrm{~m}^{-/}\right)$and CD4 and CD8 knockout C57BL/6 mice of age 5-8 weeks were purchased from Taconic Laboratories (Germantown, New York, USA) and maintained in our pathogen-free facility at the Schepens Eye Research Institute. Mice were treated according to the Association for Research in Vision and Ophthalmology resolution.

Skin transplantation. Full-thickness trunk and tail skin allografts were placed using standard techniques (18). Skin was harvested from euthanized donor mice and cut into $0.5-\mathrm{cm}$ pieces and placed in sterile PBS until used for transplantation (less than 30 minutes). Recipient mice were anesthetized with a mixture of $150 \mathrm{mg} / \mathrm{kg}$ ketamine and $6 \mathrm{mg} / \mathrm{kg}$ xylazine and shaved around the back. The skin allograft was placed in a slightly larger graft bed prepared over the back of the recipient and secured using Vaseline gauze and a bandage. Bandages were removed on day 7 , and the grafts were then visually scored daily for evidence of rejection. The allograft was considered fully rejected when it was more than $90 \%$ necrotic.

Retinal transplantation. Eyes from euthanized donor mice were enucleated and placed in ice-cold calciummagnesium-free HBSS and washed three times with fresh HBSS media. Under a surgical microscope, the anterior segment, crystalline lens, and vitreous of the eye were removed using a pair of microsurgical forceps. Following this step, retinas containing both neural retina and retinal pigment epithelium were isolated and transferred into fresh HBSS. Full-thickness retinas (from RPE layer to inner limiting membrane) were cut into 4-8 pieces that were then used for grafting. Recipient mice received general anesthesia (as described above) before the eye surgery. The donor retinal tissues were then drawn in a glass needle made from the glass bore of a $200-\mu \mathrm{m}$ diameter $10-\mu \mathrm{l}$ micropipette and microinjected in the recipient's vitreous cavity.

Histological analyses. At designated time points, recipient mice were euthanized and the eyeballs immediately enucleated. The eyes were fixed using 10\% buffered formalin solution. The eyes were then embedded in ornithine caramyltransferase compound (Sakura-Tissue-Tek, Torrance, California, USA) and prepared for $8-\mu \mathrm{m}$ cryostat sections. Cryostat sections were mounted on gelatin-coated slides and stored at $4^{\circ} \mathrm{C}$ for hematoxylin and eosin ( $\left.\mathrm{H} \& \mathrm{E}\right)$ staining. The sections were examined with an Olympus research microscope and photographed.

$T$ cell isolation. T cells were purified from single cell suspensions of mouse draining lymph nodes and spleens by negative selection using commercially available T cell isolation columns (R\&D Systems Inc., Minneapolis, Minnesota, USA) per the manufacturer's recommendations. Purified T cells were greater than $88 \%$ $\mathrm{CD}^{+}$as determined by FACS.

Preparation of stimulator cells. Irradiated (20 Gy) splenocytes were used as stimulator cells for all experiments. Single cell suspensions of splenocytes from normal mice were prepared. The cells were washed three times with HBSS and resuspended in AIM-V medium for all assays.

ELISA spot assay. Ninety-six-well ELISA spot plates (Polyfiltronics Group Inc., Rockland, Massachusetts, USA) were coated with a capture $\mathrm{mAb}$ in sterile PBS overnight. Anti-IL-2 (JES6-1A12), anti-IFN- $\gamma$ (R46A2), and anti-IL-5 (TRFK5) capture mAb were used at 3, 4, and $5 \mu \mathrm{g} / \mathrm{ml}$, respectively (PharMingen, San Diego, California, USA). On the day of the experiment, the plates were washed twice with sterile PBS, blocked for 1.5 hours with PBS containing $1 \%$ BSA, then washed three times with sterile PBS. Responder cells were added to wells previously filled with intact donor cells (direct response) or syngeneic cells together with donor sonicate (indirect response) as previously described (19). Cells were incubated for different periods of time depending on the cytokine measurement: 20 hours for IL-2, 42 hours for IFN- $\gamma$, and 48 hours for IL-5. The plates were washed three times with PBS, then four times with PBS containing $0.025 \%$ Tween (PBST). Biotinylated anti-lymphokine detection mAb's were added at $2 \mu \mathrm{g} / \mathrm{ml}$ (JES6-5H4 for IL-2, XMG1.2 for IFN- $\gamma$, and TRFK4 for IL-5; PharMingen) and incubated either for 5 hours at room temperature or overnight at $4^{\circ} \mathrm{C}$. After washing three times with PBST, avidin-horseradish peroxidase $(1: 2,000)$ was added to each well for 1.5 hours. Four washes with PBS were performed before the spots were 


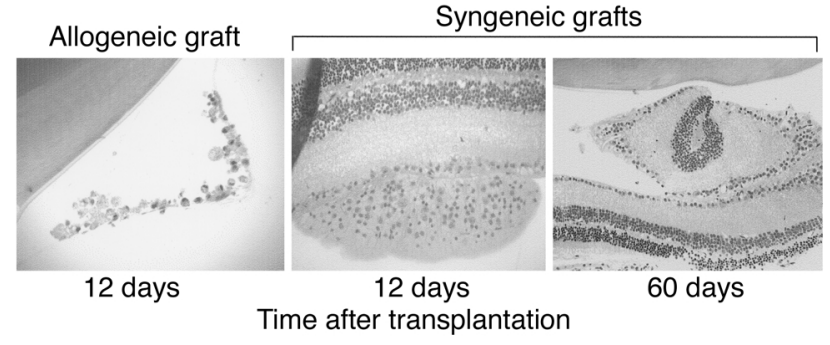

Figure 1

Histology of retinal transplants placed in the vitreous cavity of recipient mouse eyes. Retinal tissues were stained with $\mathrm{H} \& \mathrm{E}$. Allogeneic $\mathrm{C} 57 \mathrm{BL} / 6$ grafts placed in the eyes of BALB/c mice show a high degree of deterioration (at 12 days after transplantation) (left panel, $\times 400$ ). In contrast, syngeneic BALB/c retinas placed into BALB/c eyes exhibit well-preserved cell layer architecture both at 12 and 60 days after transplantation (middle and right panels, $\times 200$ ).

revealed by the addition of the developing solution composed of $800 \mu \mathrm{l}$ of 3-amino 9-ethylcarbazole (AEC) (10 $\mathrm{mg}$ dissolved in $1 \mathrm{ml}$ dimethylformamide; Sigma Chemical Co., St. Louis, Missouri, USA) in $24 \mathrm{ml}$ of $0.1 \mathrm{M}$ sodium acetate, $\mathrm{pH}$ 5.0, catalyzed by $12 \mu \mathrm{H}_{2} \mathrm{O}_{2}$. The resulting spots were counted and analyzed on a computer-assisted ELISA spot-image analyzer (Cell Technology Limited, Cleveland, Ohio, USA) (19).

\section{Results}

Allogeneic retinal transplants induce potent anti-donor $T$ cell responses in recipients. $\mathrm{BALB} / \mathrm{c}\left(\mathrm{H}-2^{\mathrm{d}}\right)$ mice were transplanted with either fully allogeneic $\mathrm{C} 57 \mathrm{BL} / 6\left(\mathrm{H}-2^{\mathrm{b}}\right)$ or syngeneic $(\mathrm{BALB} / \mathrm{c})$ adult retinas. Full-thickness retinal sheets corresponding to one-fourth to one-eighth of the whole donor retina were microinjected into the vitreous cavity of the eye of the recipient mouse. First, the fates of allogeneic and syngeneic retinal transplants were compared using histological techniques. At day 12 following transplantation, the majority of allogeneic retinas (> 60\%) were mark-edly deteriorated (cell death and loss of tissue architecture) (Figure 1, left panel). In contrast, none of the syngeneic retinal transplants examined up to 60 days after transplantation ever displayed any signs of cell death or tissue damage (Figure 1, middle and right panels). We conclude that allogeneic but not syngeneic transplanted retinas rapidly deteriorate after placement in recipient's vitreous cavity.

Figure 2
Next, we measured alloimmune responses in BALB/c mice intravitreally transplanted with allogeneic $(\mathrm{C} 57 \mathrm{BL} / 6)$ and syngeneic $(\mathrm{BALB} / \mathrm{c})$ retinas. Twelve days after transplantation, recipient mice were sacrificed and their eyes, draining (cervical) lymph nodes, and spleens were collected. Draining lymph node T cells were studied as a reflection of the environment local to the rejection site, and isolated spleen $T$ cells were studied as a reflection of the peripheral immune response. Bulk cell suspensions and purified $\mathrm{T}$ cells from recipient's lymphoid organs were prepared and placed in culture in the presence of allogeneic irradiated splenocytes. Here, we used a high-resolution ELISA spot assay to evaluate the frequency of cytokine-producing alloreactive $T$ cells after retinal transplantation. In this set of experiments, mice with skin allografts were used as positive control and naive (nontransplanted) mice as negative controls. Consistent with our results published previously (19), spleen $\mathrm{T}$ cell suspensions obtained after placement of C57BL/6 skin onto $\mathrm{BALB} / \mathrm{c}$ recipient mice responded at very high frequency ( $>2000$ IL-2 and IFN- $\gamma$ spots $/ 10^{6}$ cells) to donor C57BL/6 spleen stimulator cells (Figure 2). Mice with allogeneic retinal transplants mounted potent alloreactive $\mathrm{T}$ cell responses (Figure 2). This response was mediated by $\mathrm{T}$ cells producing type 1 (IFN- $\gamma$ and IL-2) lymphokines. In contrast, no expansion of IL-5 type 2 cytokine-producing $T$ cells was detected. Similar observations were made with lymph node $T$ cells (data not shown). Most importantly, the number of activated $\mathrm{T}$ cells in mice grafted with allogeneic retinas was clearly much higher (> 1000 spots $/ 10^{6}$ cells) than the frequencies of cytokine-producing $\mathrm{T}$ cells detected in both naive mice and mice with syngeneic retinal transplants

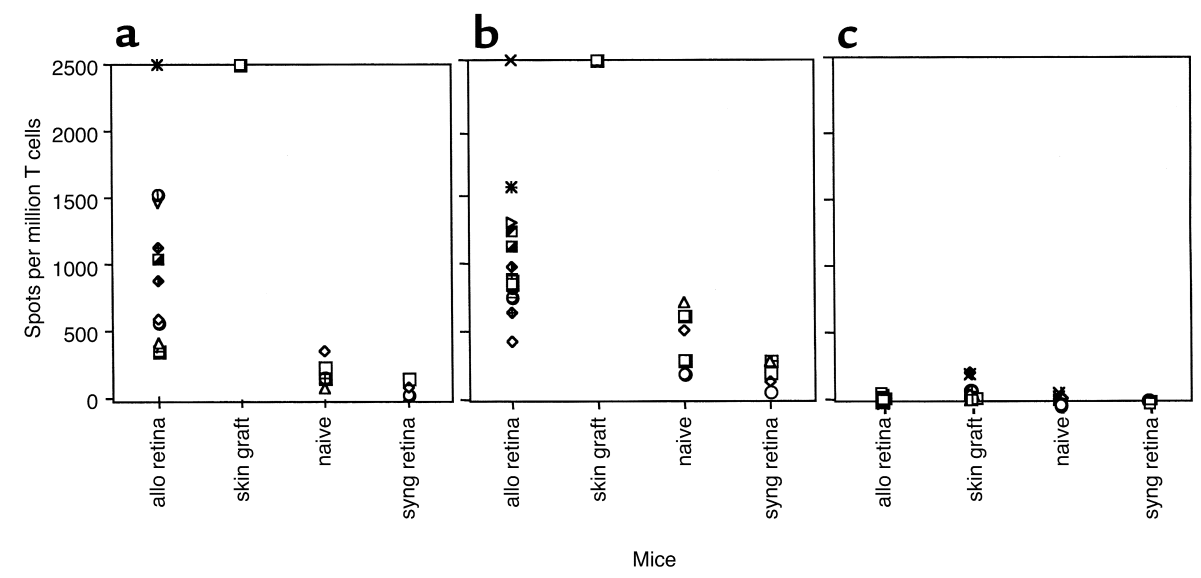

Intravitreal transplantation of allogeneic retinas induces potent immune responses in recipient mice. Recipient BALB/c mice were transplanted with allogeneic (B6) retinas (allo retina), syngeneic retinas (syng retina), or allogeneic skins (skin graft). Nontransplanted mice were used as controls (naive). Ten to nineteen days after transplantation, spleen recipient $\mathrm{T}$ cells were restimulated in vitro with irradiated donor splenocytes for 20-24 hours for IL-2 and 40-44 hours for IFN- $\gamma$ and IL-5. The frequency of (a) IFN- $\gamma-$, (b) IL-2-, and (c) IL-5-producing T cells was measured using the ELISA spot technique. The data are expressed as cytokine-producing spots per million T cells. The IFN- $\gamma$ and $\mathrm{IL}-2$ results obtained after skin grafting (> 2,500 spots/million T cells) are representative of six mice tested individually. In all other cases, each individual symbol corresponds to one mouse. 


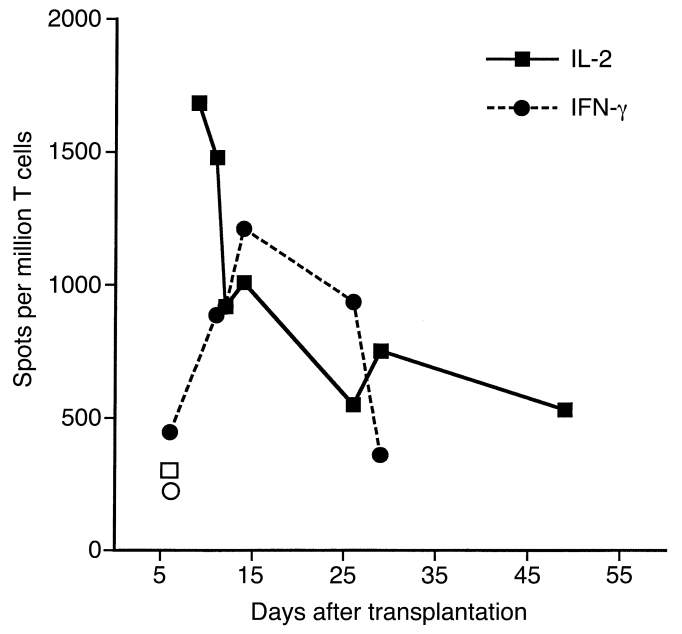

(<200 spots $/ 10^{6}$ cells) (Figure 2). It is noteworthy that the high frequency of activated T cells found in retinalgrafted mice is consistent with a direct alloimmune response (to intact donor MHC), a type of response known for its polyclonality and polyspecificity (20-22). Indeed, the assays shown in Figure 2 were performed with purified recipient $T$ cells exposed to donor irradiated APCs, a setting that measures only the direct response (19). In another set of experiments, we investigated the presence of an indirect alloresponse (recipient APCs presenting donor-derived peptides) in retinal-grafted mice. To test this, purified recipient $\mathrm{T}$ cells were cultured with recipient APCs and donor-derived sonicates (19). Strikingly, no T cell response was found (data not shown). Altogether, our data demonstrate that the alloresponse in this model is mediated via the presentation of alloantigen by donor APCs only, i.e., via direct allorecognition.

In both skin- and retinal-allografted mice, high frequencies of IL-2-producing $T$ cells were detected after 24 hours in culture, a feature characteristic of preactivated $\mathrm{T}$ cells. This observation further demonstrated that these $T$ cells had been sensitized by the alloantigen in vivo following transplantation. We conclude that allogeneic retinal grafts placed in the vitreous cavity of mice are recognized by the host's immune system and elicit vigorous immune responses characterized by the expansion and differentiation of high numbers of $\mathrm{T}$ cells secreting type 1 (IL-2 and IFN- $\gamma$ ) lymphokines.

\section{Figure 4}

Alloreactive $\mathrm{T}$ cell responses in mice grafted with retinas devoid of MHC class I and class II molecules. The number of IL-2-secreting (a) and IFN- $\boldsymbol{\gamma}$-secreting (b) T cells was evaluated in recipient BALB/c mice transplanted with retinal grafts from wild-type $\mathrm{B} 6$ (positive control), B6 class I KO ( $\beta_{2} \mathrm{~m}^{-/-} ; \mathrm{B} 6 \mathrm{Cl}$ I KO$)$, and $\mathrm{B} 6 \mathrm{Cl}$ II KO donors. T cells from naive, nontransplanted $B A L B / c$ mice were used as negative control. In all experiments, $T$ cells were restimulated in vitro with B6 irradiated splenocytes. Each symbol represents an individual mouse. The data are expressed as cytokine-producing spots per million T cells.

\section{Figure 3}

Kinetics of the immune response in the spleen of retina-transplanted mice. T cells from mice grafted with allogeneic retinas were harvested at different time points after transplantation. T cells were restimulated in vitro with donor irradiated splenocytes. The frequency of IFN- $\gamma$-producing (filled circles) and IL-2-producing (filled squares) T cells was determined using ELISA spot methodology. The data are expressed as cytokine-producing spots per million T cells. Open symbols represent the frequency of IFN- $\gamma$-producing (open circle) and IL-2-producing (open square) T cells in control naive mice. Each point represents the average number of spots from three to six mice tested individually.

To evaluate the kinetics of the alloresponse, we next determined the frequency of donor-specific cytokineproducing $\mathrm{T}$ cells at various time points after placement of retinal allografts in mice. To address that, IL- 2 and IFN- $\gamma$ T cell responses to irradiated allogeneic cells were monitored by the ELISA spot method from day 9 through day 55 after transplantation. We observed that while initial $\mathrm{T}$ cell response was high (1,700 IL-2 spots per million T cells), it decreased at later time points (Figure 3). It is, however, important to note that even at day 50 after retinal transplantation, the number of activated T cells producing IL-2 was still elevated (600 spots per million T cells) and significantly higher than in nontransplanted mice (IL-2: 300 spots). This suggests that, after complete deterioration of retinal transplants had occurred, donor-specific memory $\mathrm{T}$ cells persisted in recipient mouse spleens, a phenomenon that has also been described in other types of transplantation (23).

Contribution of MHC class I and II expression on retinal allografts on Tcell alloresponse in recipient mice. We investi-

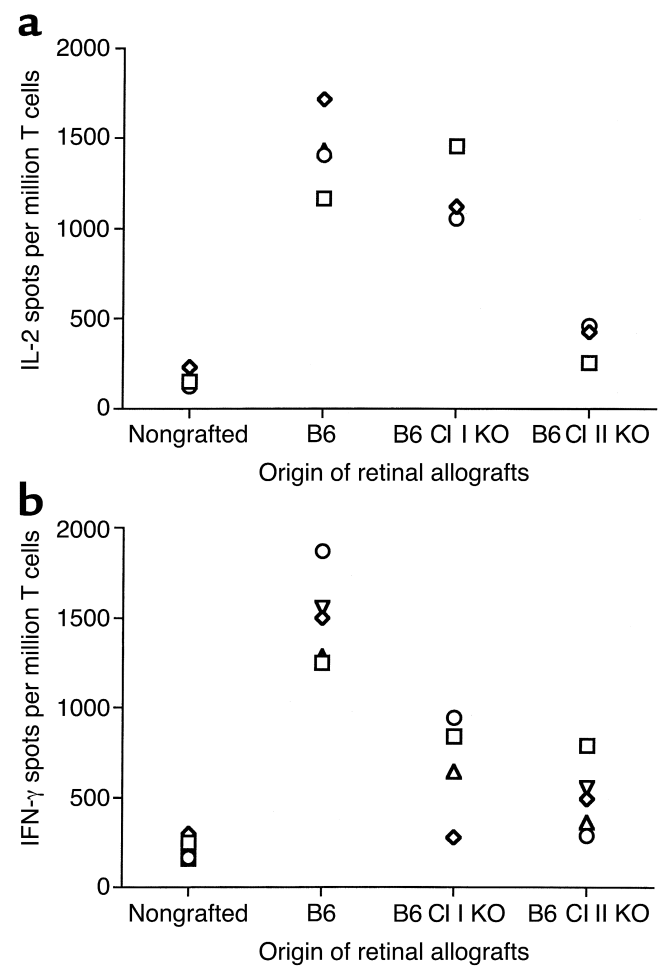




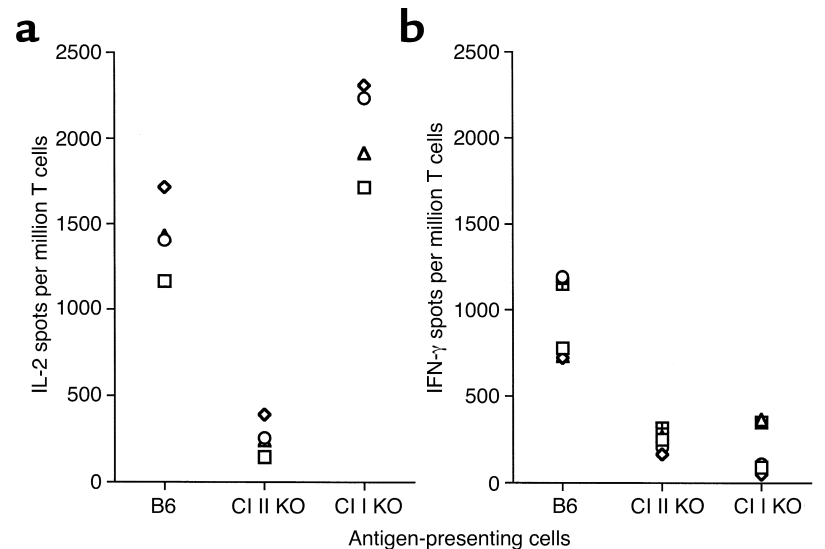

\section{Figure 5}

Alloreactive responses of T cells from retinal-grafted mice restimulated in vitro with donor APCs lacking MHC class I and class II expression. The number of IL-2-secreting (a) and IFN- $\gamma$-secreting (b) $T$ cells was evaluated in BALB/c mice transplanted with retinal grafts from wild-type $B 6$ mice. Recipient $T$ cells were restimulated in vitro with wild-type B6 irradiated cells (positive control) or with donor APCs devoid of either MHC class I or class II expression. The average frequencies of IL-2-producing and IFN- $\gamma$-producing cells responding to allogeneic wild-type B6 stimulators in nontransplanted mice was $500 \pm 150$ and $240 \pm 120$ spots, $n=15$, respectively (negative controls). Each symbol represents an individual mouse. The data are expressed as cytokine-producing spots per million T cells.

gated the contribution of allogeneic MHC class I and II molecules on donor cells to the rejection of retinal allografts. BALB/c mice were engrafted with retinas from C57BL $/ 6$ mice lacking either MHC class I $\left(\beta_{2} \mathrm{~m}\right)$ or II gene expression (MHC knockout). Ten to twelve days after transplantation, recipient all-immune response to B6 allostimulator cells was measured by the ELISA spot method (IL-2 and IFN- $\gamma$ ). Vigorous IL-2 T cell response, comparable to those observed after placement of wildtype grafts, was detected in recipients transplanted with allogeneic retinas devoid of MHC class I (Figure $4 a)$. In contrast, the frequency of IL-2 cytokine-producing alloreactive $\mathrm{T}$ cells in recipients grafted with retinas lacking MHC class II expression was reduced to a level comparable to that measured in naive, nontransplanted mice (Figure 4a). Alternatively, absence of either MHC class I or MHC class II resulted in marked reduction of IFN- $\gamma$ production by $\mathrm{T}$ cells in retinal transplanted mice (percentages of reduction: MHC class I knockout (KO): $54.2 \pm 11.23 \%, P<0.001$; MHC class II KO: $64.6 \pm 5.25 \%, P<0.001$ ) (Figure $4 \mathrm{~b}$ ).

In another set of experiments, $\mathrm{BALB} / \mathrm{c}$ mice were transplanted with wild-type B6 retinas. To further explore the influence of donor MHC class I and II on the nature of $\mathrm{T}$ cell response in retinal-grafted mice, recipient spleen $\mathrm{T}$ cells were restimulated in vitro with B6 stimulator cells lacking either MHC class I or II expression. Recipient $\mathrm{T}$ lymphocytes restimulated in vitro with wild-type $\mathrm{B} 6$ retinas were used as positive controls. As shown in Figure 5a, absence of MHC class II but not class I on donor APCs resulted in complete abrogation of IL-2 production by alloreactive T cells. In turn, the frequencies of IFN- $\gamma$-secreting cells were reduced to background levels (nontransplanted mice) following in vitro exposure of recipient $\mathrm{T}$ cells to both MHC class I-and II-deficient donor APCs (Figure 5b).

We conclude that absence of MHC class II but not class I on the grafted retina (in vivo) and on donorderived stimulator cells (in vitro) invariably leads to abrogation of IL-2 production by recipient alloreactive $\mathrm{T}$ cells. Alternatively, our results demonstrate that both MHC class I and II expression on donor cells are necessary for the expansion of alloreactive $T$ cells secreting IFN- $\gamma$ in retinal-transplanted mice. Indeed, it is well known that allogeneic MHC class II molecules displayed on grafted cells are recognized by $\mathrm{CD} 4^{+} \mathrm{T}$ cells while donor MHC class I triggers $\mathrm{CD}^{+} \mathrm{T}$ cell response $(24,25)$. It is therefore likely that absence of MHC class II and class I on donor retinas had abolished $\mathrm{CD}^{+}$and $\mathrm{CD}^{+} \mathrm{T}$ cell responses, respectively. The observation that retinas devoid of MHC class II did not trigger any $\mathrm{T}$ cell response, neither $\mathrm{CD} 4$ nor $\mathrm{CD} 8$ mediated, suggests that $\mathrm{CD}^{+} \mathrm{T}$ cell help in the form of IL-2 was required for activation/differentiation of $\mathrm{CD}^{+} \mathrm{T}$ cells.

Absence of MHC class II but not class I expression on retinal allografts results in their lack of deterioration. Finally, retinal transplants from $\mathrm{BALB} / \mathrm{c}$ mice grafted with wild-type and MHC class I and II $\mathrm{KO}$ were examined histologically. Strikingly, while MHC class I-negative retinal allografts displayed deterioration after 15 days (Figure 6, right panel), the majority of transplants devoid of MHC class II were preserved (Figure 6, left panel). We conclude that expression of MHC class II but not MHC class I governs the deterioration of retinal allotransplants in recipient mice. This suggests that MHC class II-restricted $\mathrm{CD}^{+} \mathrm{T}$ cells, but not MHC class I-restricted $\mathrm{CD}^{+} \mathrm{T}$ cells, are necessary and sufficient to initiate an immune process leading to retinal graft deterioration.

Differential contribution of $\mathrm{CD} 4^{+}$and $C D 8^{+} T$ cells to the immune response to allogeneic retinal transplants. We next examined the role of $\mathrm{CD}^{+}$and $\mathrm{CD}^{+} \mathrm{T}$ cell subsets in the alloimmune response to retinal allografts in mice. To address this, BALB/c mice were transplanted with allogeneic C57BL/6 retinas. Twelve days later, recipient spleen cells were placed in culture in the presence of allogeneic stimulators and anti-CD4 or anti-CD8

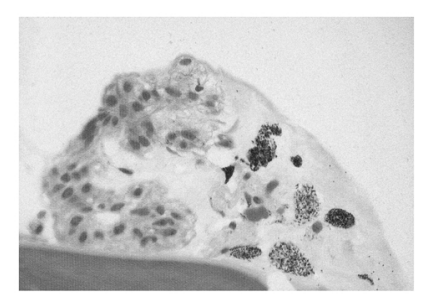

$\mathrm{MHC} \mathrm{II}^{-}$retinal graft

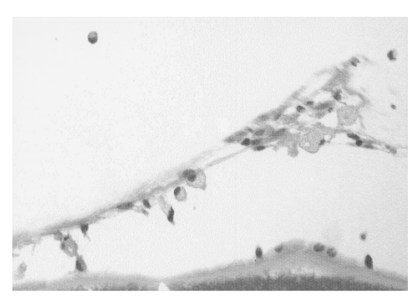

$\beta_{2} \mathrm{~m}^{-}$retinal graft

\section{Figure 6}

Histology of MHC class II and MHC class I KO $\left(\beta_{2} \mathrm{~m} \mathrm{KO}\right)$ allogeneic (B6) retinal grafts placed in the vitreous cavity of BALB/c recipients. Retinal tissues were collected 12 days after transplantation and stained with $\mathrm{H} \& \mathrm{E}$. 


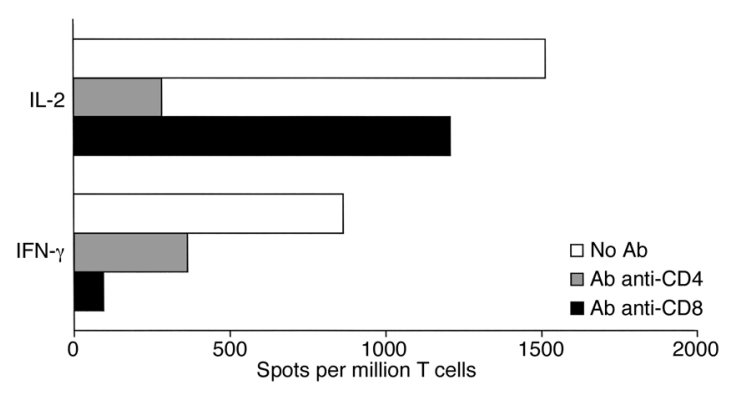

Figure 7

Effects of anti-CD4 and anti-CD8 Ab treatments on alloimmune responses induced after retinal allotransplantation. T cells from retinal-allotransplanted $(B A L B / c)$ mice were restimulated in vitro with donor $\mathrm{B} 6$ irradiated splenocytes in the presence of anti-CD4 or antiCD8 mAb's $(2 \mu \mathrm{g} / \mathrm{ml})$. The frequency of IL-2- and IFN- $\gamma$-producing $\mathrm{T}$ cells was measured by the ELISA spot method and the results expressed as spots per million $T$ cells. The data shown here are representative of four separate experiments. The data show the frequency of cytokine-producing spots per million T cells.

mAb's. Anti-donor immune response was then investigated using the ELISA spot technique. As shown in Figure 7 , anti-CD4 $\mathrm{mAb}$ abolished the expansion of IL-2-producing $\mathrm{T}$ cells and significantly reduced the number of alloreactive T cells secreting IFN- $\gamma$. In contrast, treatment with anti-CD8 $\mathrm{mAb}$ had negligible effect on IL-2 production while it abrogated activation of IFN- $\gamma$-secreting T cells (Figure 7).

Finally, we used genetically engineered mice to further investigate the contribution of $\mathrm{CD}^{+}$and $\mathrm{CD}^{+} \mathrm{T}$ cells to the alloresponse after retinal allotransplantation. $\mathrm{B} 6$ mice lacking either $\mathrm{CD} 4$ or $\mathrm{CD} 8 \mathrm{~T}$ cell surface coreceptors (B6, CD4 KO, and $\mathrm{CD} 8 \mathrm{KO}$ ) were used as recipients and transplanted with $\mathrm{BALB} / \mathrm{c}$ allogeneic retinas. Consistent with our previous observations, no expansion of IL-2-producing T cells were detected in CD4 KO mice (Figure 8). In contrast, absence of CD8 coreceptor expression on recipient's $\mathrm{T}$ lymphocytes had no inhibitory effect on IL-2 production (Figure 8, upper panel). Alternatively, a marked reduction in the frequency of IFN- $\gamma$-secreting $\mathrm{T}$ cells was found in transplanted mice devoid of $\mathrm{CD}^{+}$, while significant IFN- $\gamma$ production was still found in $\mathrm{T}$ cells derived from CD4 KO mice (Figure 8, lower panel).

It is noteworthy that some IFN- $\gamma$ could be detected in CD8 KO mice transplanted with allogeneic retinas. Three nonexclusive explanations may account for this observation: (a) some evidence has been provided suggesting the possible presence of a very small population of T cells $(3 \%)$ expressing CD8 intracellularly in $\mathrm{CD} 8 \mathrm{KO}$ mice (26), (b) some non-CD8 ${ }^{+} \mathrm{T}$ cells such as natural killer (NK) cells or double-negative $T$ cells may secrete some IFN- $\gamma(27,28)$, and (c) it is likely that some compensatory mechanisms are present in $\mathrm{KO}$ mice. For instance, we have observed previously that in CD4 KO mice one can find more CD4-independent CD8 $\mathrm{T}$ cells that produce their own IL-2, thereby compensating for the absence of $\mathrm{CD} 4^{+} \mathrm{T}$ cell help (29).
Likewise, in $\mathrm{CD} 8 \mathrm{KO}$ mice, it is possible that some $\mathrm{CD}^{+} \mathrm{T}$ cells make more IFN- $\gamma$ than in normal mice.

It is at first glance surprising that the treatment with anti-CD4 mAb completely abrogated the production of IFN- $\gamma$ by $\mathrm{CD}^{+} \mathrm{T}$ cells while $\mathrm{CD} 4 \mathrm{KO}$ mice produce normal IFN- $\gamma$ levels. We believe that in normal mice $\mathrm{CD}^{+} \mathrm{T}$ cells require help from $\mathrm{CD} 4^{+} \mathrm{T}$ cells in the form of IL- 2 in order to produce IFN- $\gamma$ and eventually differentiate into functional cytotoxic $\mathrm{T}$ cells. However, in $\mathrm{CD} 4 \mathrm{KO}$ mice, $\mathrm{CD}^{+} \mathrm{T}$ cells seem to compensate for the absence of $\mathrm{CD}^{+} \mathrm{T}$ cells by sustaining their own activation in the absence of IL-2 or in the presence of very low IL-2 levels, a phenomenon we have observed previously in corneal transplantation as well (29).

Taken together, these results demonstrate that immune responses to allogeneic retinal grafts is mediated by two functionally distinct $\mathrm{T}$ cell subsets: $\mathrm{CD} 4^{+}$ $\mathrm{T}$ cells secreting IL-2 and $\mathrm{CD}^{+} \mathrm{T}$ cells secreting IFN- $\gamma$. It is likely that expansion of $\mathrm{CD}^{+} \mathrm{T}$ cells requires IL-2 provided by activated $\mathrm{CD} 4^{+} \mathrm{T}$ cells. However, some IFN- $\gamma$-producing T cells were still detected with wild-type $T$ cells incubated with anti-CD4 $\mathrm{mAb}$ and also with $\mathrm{T}$ cells from $\mathrm{CD} 4 \mathrm{KO}$ mice. These results suggest that, in retinal-transplanted mice, a small fraction of $\mathrm{CD}^{+} \mathrm{T}$ cells can become activated in the absence of $\mathrm{CD}^{+} \mathrm{T}$ cell help.
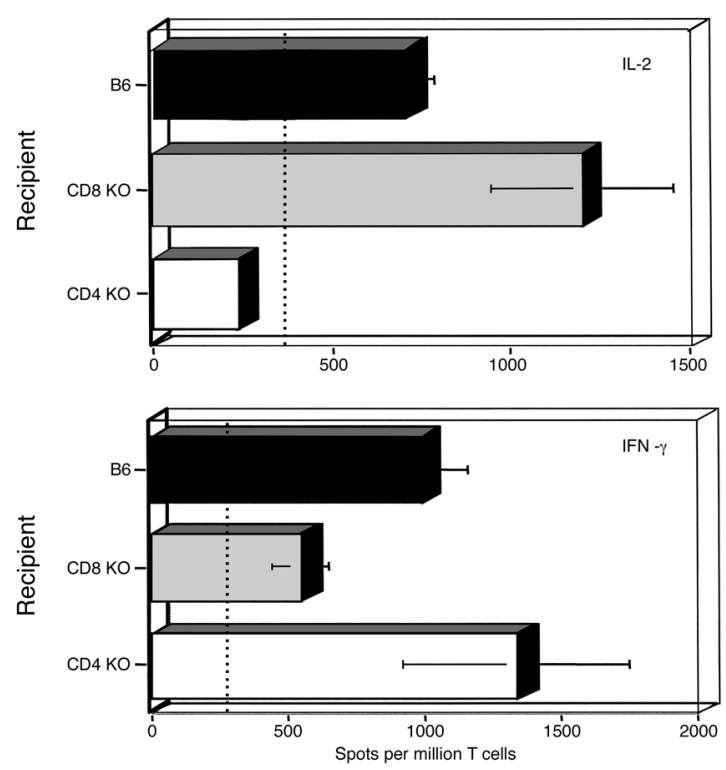

\section{Figure 8}

Alloimmune responses to retinal allografts in recipient mice devoid of CD4 and CD8 T cell subsets. Wild-type (B6) as well as CD4 KO and $\mathrm{CD} 8 \mathrm{KO}$ mice were used as recipients. After intravitreal grafting with allogeneic $(B A L B / c)$ retinas, recipient $T$ cells were purified and incubated in vitro with donor irradiated spleen cells. The frequency of activated T cells releasing IL-2 (upper panel) and IFN- $\gamma$ (lower panel) cytokines was determined by the ELISA spot method. The dotted line represents the frequencies of cytokine-producing $T$ cells obtained in naive B6 mice. The data shown represent the mean number of cytokine-producing spots (per million T cells) \pm SD obtained with six to seven mice tested separately. 


\section{Discussion}

During the past 10 years, a number of studies have shown that orthotopic transplantation of various retinal sheets, including retinal pigment epithelium and neuronal retina, can be achieved in animal models (1-9). Moreover, some evidence has been provided showing that these retinal grafts can restore certain functions, including the rescue of photoreceptors undergoing degeneration in RCS rats $(7,10,30)$. However, these beneficial effects are usually temporary owing to the rapid deterioration of retinal grafted tissues. The mechanisms by which transplanted retinas deteriorate are still unknown. It has been initially assumed that retinal allografts placed orthotopically do not elicit any alloimmune response and do not suffer immune rejection. This assumption was based upon the fact that retinal tissues express low levels of MHC molecules. In addition, a number of studies have underscored the immune privilege nature of the eye. This feature of the eye is due to the presence of (a) the blood/ocular barrier, (b) local immunosuppressive factors, and (c) activation of some immunoregulatory $\mathrm{T}$ cells $(12,13,31)$. Indeed, a number of scientists have reported that retinal grafts can survive for extended periods of time in rodent's eyes (> 60 days). It is noteworthy, however, that many of these studies were performed using animals transplanted with syngeneic retinas and treated with massive doses of immunosuppressive drugs (cyclosporine A). In turn, no in-depth analysis of the immune response in allografted individuals has been performed to demonstrate that these transplants are actually not immunogenic.

Several lines of evidence have been provided recently by work from Jiang's and Streilein's laboratories showing that the initial assumption of lack of immunogenicity of retinal allografts is perhaps incorrect. First, it was observed that allogeneic retinal transplants performed in mice deteriorate faster that their syngeneic counterparts $(14,17,32)$. Second, retinal allografts induced delayed-type hypersensitivity $(\mathrm{DTH})$ reactions detectable in host peripheral lymphoid organs (14). In addition, upregulation of MHC class I and II expression on donor microglial cells was detected after transplantation of neonatal neural retinas $(33,34)$. Although this phenomenon was observed after placement of both allogeneic and syngeneic retinal transplants, only MHC class II expression on allogeneic microglia played a role in host sensitization and graft deterioration $(33,34)$. Taken together, these observations suggested that allogeneic retinal allografts placed in different compartments of the eye may be immunogenic.

In this article, we have demonstrated that allogeneic retinas placed in the vitreous cavity of mice are recognized by the host's immune system. We showed that allogeneic but not syngeneic retinal grafts induce potent $\mathrm{T}$ cell responses to donor antigens characterized by the expansion of alloreactive $T$ cells secreting type $1 \mathrm{lym}-$ phokines (IFN- $\gamma$ and IL-2). Importantly, we observed that syngeneic retinal grafts were intact even 60 days after transplantation. In contrast, the majority of allogeneic transplants suffered progressive deterioration detectable within 2 weeks after grafting. It is noteworthy, however, that some retinal transplants, despite their ability to induce an immune response, did not display any signs of tissue damage. Taken together, these observations show that retinal allografts are immunogenic and that the responses they trigger in recipients are necessary but not always sufficient to mediate retinal tissue deterioration. In retinal-transplanted mice, alloreactive $\mathrm{T}$ cell responses were mediated by two phenotypically and functionally distinct $\mathrm{T}$ cell subsets: $\mathrm{CD} 4^{+} \mathrm{T}$ cells secreting IL-2 and $\mathrm{CD}^{+} \mathrm{T}$ cells producing IFN- $\gamma$. This finding corroborates recent studies in Lehmann's laboratory and other laboratories also measuring cytokine production at a single cell level, which demonstrated that individual activated $\mathrm{T}$ cells secrete only one lymphokine $(35,36)$. In normal mice, absence of $\mathrm{CD}^{+} \mathrm{T}$ cell response resulted in abrogation of $\mathrm{CD}^{+} \mathrm{T}$ cell-mediated secretion of IFN- $\gamma$, a result suggesting that $\mathrm{CD}^{+} \mathrm{T}$ cell response is dependent upon activation of $\mathrm{CD}^{+} \mathrm{T}$ cells. In some circumstances, however, including transplantation of CD4 $\mathrm{KO}$ mice, we found that $\mathrm{CD}^{+} \mathrm{T}$ cells produced some IFN- $\gamma$. This suggests that some compensatory mechanisms may exist in genetically engineered mice enhancing the ability of $\mathrm{CD}^{+} \mathrm{T}$ cells to produce IFN- $\gamma$ when $\mathrm{CD}^{+} \mathrm{T}$ cells are missing. Strikingly, the absence of MHC class I molecules on donor retinas had no influence on the deterioration of retinal allografts. In contrast, MHC class $\mathrm{II}^{-/-}$transplants suffered much less deterioration than their wild-type counterparts. This observation shows that MHC class II-restricted $\mathrm{CD}^{+} \mathrm{T}$ cells represent the main driving force in the immune process associated with the deterioration of orthotopic retinal transplants.

$T$ cell response to allogeneic transplants is traditionally mediated via two distinct pathways: direct allorecognition, in which $\mathrm{T}$ cells recognize intact allogeneic MHC molecules displayed on donor cells (19-22, 25, 37, 38), and indirect alloresponse, in which $T$ cells interact with donor-derived peptides presented by self-MHC on recipient APCs $(25,39-46)$. Direct alloresponse is polyspecific and polyclonal while indirect alloresponse is oligoclonal and limited to the recognition of a few dominant donor-derived peptides $(20,21)$. The high frequency of $\mathrm{CD}^{+}$alloreactive $\mathrm{T}$ cells activated after retinal transplantation is consistent with induction of a direct alloresponse in recipient's lymphoid organs. This implies that the retina contains bone marrow-derived $\mathrm{MHC}$ class $\mathrm{II}^{+}$cells capable of migrating from the graft to the host's lymph nodes and spleen where they present intact allogeneic MHC molecules to $\mathrm{T}$ cells (passenger leukocytes) (47-49). A recent report by $\mathrm{Ma}$ and Streilein suggests that microglia that constitutively express MHC class II may play a key role in this process $(33,34)$. Indeed, a number of studies indicate that microglial cells can migrate out of the CNS and present autoantigens in a number of autoimmune neurodegenerative diseases, including 
multiple sclerosis (50-55). Taken together with our work, this strongly suggests that microglial cells act as professional APCs and are likely to serve as passenger leukocytes in retinal-transplanted mice.

The transplantation of cells and tissues derived from the CNS represents a promising approach for the prevention and the treatment of a number of degenerative neurological diseases. If such an approach were to be considered for human diseases, it is most likely that potential donor tissues would be derived from genetically disparate and therefore histoincompatible individuals. It has become increasingly clear that the immune privilege status of the eye and the CNS altogether is neither absolute nor eternal. It is known that a number of CNS diseases, including multiple sclerosis, are invariably associated with alteration of the blood-brain barrier. Likewise, disruption of the bloodocular barrier (BOB) and neovascularization have been reported in individuals with a variety of eye diseases. This has been observed in age-related diseases including macular degeneration and in retinitis pigmentosa, as well as in a series of diseases caused by trauma, infection, and tissue damage. Such disruption of the bloodtissue barriers presumably contributes to loss of immune privilege and subsequent induction of inflammatory and autoimmune disorders in the eye and the CNS. This indicates that in patients with eye diseases associated with loss of immune privilege, disruption of the $\mathrm{BOB}$, and/or neovascularization, it is likely that retinal transplants will be efficiently rejected by the recipient's immune system. Indeed, our study demonstrates that retinal allografts are immunogenic and that the host's immune system contributes to the deterioration of these transplants. As we gain insights into the mechanisms underlying the immune response induced after retinal transplantation, we will determine the best strategy to successfully transplant retinas and other neuronal tissues.

\section{Acknowledgments}

We would like to thank S. Whiteley for his help with retinal transplantation procedures and V. Chau for her technical assistance. We also thank J.W. Streilein for helpful discussions. This work was supported by a grant from the Minda de Gunzburg Foundation to G. Benichou. B. Illigens was supported in part by a fellowship from Studienstiftung des Deutschen Volkes, Germany.

1. Algvere, P.V., Berglin, L., Gouras, P., and Sheng, Y. 1994. Transplantation of fetal retinal pigment epithelium in age-related macular degeneration with subfoveal neovascularization. Graefes Arch. Clin. Exp. Ophthalmol. 232:707-716.

2. del Cerro, M., et al. 1989. Retinal transplants for cell replacement in phototoxic retinal degeneration. Prog. Clin. Biol. Res. 314:673-686.

3. del Cerro, M., et al. 1988. Retinal transplants into adult eyes affected by phototoxic retinopathy. Prog. Brain Res. 78:125-130.

4. Gouras, P., Flood, M.T., Kjedbye, H., Bilek, M.K., and Eggers, H. 1985

Transplantation of cultured human retinal epithelium to Bruch's membrane of the owl monkey's eye. Curr. Eye Res. 4:253-265.

5. Gouras, P., and Lopez, R. 1989. Transplantation of retinal epithelial cells. Invest. Ophthalmol. Vis. Sci. 30:1681-1683.

6. Gouras, P., Lopez, R., Brittis, M., and Kjeldbye, H. 1992. The ultrastruc- ture of transplanted rabbit retinal epithelium. Graefes Arch. Clin. Exp. Ophthalmol. 230:468-475.

7. Lopez, R., et al. 1989. Transplanted retinal pigment epithelium modifies the retinal degeneration in the RCS rat. Invest. Ophthalmol. Vis. Sci. 30:586-588.

8. Lopez, R., Gouras, P., Brittis, M., and Kjeldbye, H. 1987. Transplantation of cultured rabbit retinal epithelium to rabbit retina using a closed-eye method. Invest. Ophthalmol. Vis. Sci. 28:1131-1137.

9. Sharma, R.K., and Ehinger, B. 1997. Retinal cell transplants: how close to clinical application? Acta Ophthalmol. Scand. 75:355-363.

10. Li, L.X., and Turner, J.E. 1988. Transplantation of retinal pigment epithelial cells to immature and adult rat hosts: short- and long-term survival characteristics. Exp. Eye Res. 47:771-785.

11. Yamaguchi, K., Gaur, V.P., and Turner,J.E. 1993. Retinal pigment epithelial cell transplantation into aging retina: a possible approach to delay age-related cell death. Jpn. J. Ophthalmol. 37:16-27.

12. Streilein, J.W. 1999. Regional immunity and ocular immune privilege. Chem. Immunol. 73:11-38.

13. Streilein, J.W. 1999. Immunologic privilege of the eye. Springer Semin. Immunopathol. 21:95-111.

14. Jiang, L.Q., and Streilein, J.W. 1991. Immune responses elicited by transplantation and tissue-restricted antigens expressed on retinal tissues implanted subconjunctivally. Transplantation. 52:513-519.

15. Jiang, L.Q., Jorquera, M., and Streilein, J.W. 1993. Subretinal space and vitreous cavity as immunologically privileged sites for retinal allografts. Invest. Ophthalmol. Vis. Sci. 34:3347-3354.

16. Jiang, L.Q., Jorquera, M., and Streilein, J.W. 1994. Immunologic consequences of intraocular implantation of retinal pigment epithelial allografts. Exp. Eye Res. 58:719-728.

17. Jiang, L.Q., Jorquera, M., Streilein, J.W., and Ishioka, M. 1995. Unconventional rejection of neural retinal allografts implanted into the immunologically privileged site of the eye. Transplantation. 59:1201-1207.

18. Billingham, R.E., and Medawar, P.D. 1951. The technique of free skin grafting in mammals. J. Exp. Biol. 28:385.

19. Benichou, G., Valujskikh, A., and Heeger, P.S. 1999. Contributions of direct and indirect $T$ cell alloreactivity during allograft rejection in mice. J. Immunol. 162:352-358.

20. Ashwell, J.D., Chen, C., and Schwartz, R.H. 1986. High frequency and nonrandom distribution of alloreactivity in $\mathrm{T}$ cell clones selected for recognition of foreign antigen in association with self class II molecules. J. Immunol. 136:389-395.

21. Matzinger, P., and Bevan, M.J. 1977. Hypothesis: why do so many lymphocytes respond to major histocompatibility antigens? Cell. Immunol. 29:1-5.

22. Lombardi, G., Sidhu, S., Batchelor, J.R., and Lechler, R.I. 1989. Allorecognition of DR1 by T cells from a DR4/DRw13 responder mimics selfrestricted recognition of endogenous peptides. Proc. Natl. Acad. Sci. USA. 86:4190-4194.

23. Matesic, D., Lehmann, P.V., and Heeger, P.S. 1998. High-resolution characterization of cytokine-producing alloreactivity in naive and allograftprimed mice. Transplantation. 65:906-914.

24. Lee, R.S., et al. 1997. CD8+ effector cells responding to residual class I antigens, with help from CD4+ cells stimulated indirectly, cause rejection of "major histocompatibility complex-deficient" skin grafts. Transplantation. 63:1123-1133.

25. Sayegh, M.H., Watschinger, B., and Carpenter, C.B. 1994. Mechanisms of $\mathrm{T}$ cell recognition of alloantigen. The role of peptides. Transplantation. 57:1295-1302.

26. Fung-Leung, W.P., et al. 1991. CD8 is needed for development of cytotoxic T cells but not helper T cells. Cell. 65:443-449.

27. Cooper, M.A., et al. 2001. Human natural killer cells: a unique innate immunoregulatory role for the CD56(bright) subset. Blood. 97:3146-3151.

28. Sugie, T., et al. 1996. NK 1+ CD4- CD8- alphabeta T cells in the peritoneal cavity: specific $\mathrm{T}$ cell receptor-mediated cytotoxicity and selective IFN-gamma production against B cell leukemia and myeloma cells. J. Immunol. 157:3925-3935.

29. Boisgerault, F., et al. 2001. Role of CD4(+) and CD8(+) T cells in allorecognition: lessons from corneal transplantation. J. Immunol. 167:1891-1899.

30. Yamamoto, S., Du, J., Gouras, P., and Kjeldbye, H. 1993. Retinal pigment epithelial transplants and retinal function in RCS rats. Invest. Ophthalmol. Vis. Sci. 34:3068-3075.

31. Wauben, M.H., et al. 1992. Disease inhibition by major histocompatibility complex binding peptide analogues of disease-associated epitopes: more than blocking alone. J. Exp. Med. 176:667-677.

32. Jiang, L.Q., and del Cerro, M. 1992. Reciprocal retinal transplantation: a tool for the study of an inherited retinal degeneration. Exp. Neurol. 115:325-334.

33. Ma, N., and Streilein, J.W. 1998. Contribution of microglia as passenger leukocytes to the fate of intraocular neuronal retinal grafts. Invest. Ophthalmol. Vis. Sci. 39:2384-2393. 
34. Ma, N., and Streilein, J.W. 1999. T cell immunity induced by allogeneic microglia in relation to neuronal retina transplantation. J. Immunol. 162:4482-4489.

35. Karulin, A.Y., Hesse, M.D., Tary-Lehmann, M., and Lehmann, P.V. 2000. Single-cytokine-producing CD4 memory cells predominate in type 1 and type 2 immunity. J. Immunol. 164:1862-1872.

36. Caruso, A., et al. 1998. Segregation of type 1 cytokine production in human peripheral blood lymphocytes: phenotypic differences between IFN-gamma and IL-2-producing cells in the CD8+ T cell subset. Eur. J. Immunol. 28:3630-3638.

37. Krensky, A.M., and Clayberger, C. 1993. The nature of allorecognition. Curr. Opin. Nephrol. Hypertens. 2:898-903.

38. Benichou, G., and Fedoseyeva, E.V. 1996. The contribution of peptides to T cell allorecognition and allograft rejection. Int. Rev. Immunol. 13:231-243.

39. Benichou, G., Takizawa, P.A., Olson, C.A., McMillan, M., and Sercarz, E.E. 1992. Donor major histocompatibility complex (MHC) peptides are presented by recipient MHC molecules during graft rejection. J. Exp. Med. 175:305-308.

40. Valujskikh, A., and Heeger, P.S. 2000. CD4+ T cells responsive through the indirect pathway can mediate skin graft rejection in the absence of interferon-gamma. Transplantation. 69:1016-1019.

41. Lee, R.S., Grusby, M.J., Glimcher, L.H., Winn, H.J., and Auchincloss, H., Jr. 1994. Indirect recognition by helper cells can induce donor-specific cytotoxic T lymphocytes in vivo. J. Exp. Med. 179:865-872.

42. Benichou, G., Tam, R.C., Soares, L.R., and Fedoseyeva, E.V. 1997. Indirect T-cell allorecognition: perspectives for peptide-based therapy in transplantation. Immunol. Today. 18:67-71.

43. Fangmann, J., Dalchau, R., and Fabre, J.W. 1992. Rejection of skin allografts by indirect allorecognition of donor class I major histocompatibility complex peptides. J. Exp. Med. 175:1521-1529.

44. Liu, Z., Braunstein, N.S., and Suciu-Foca, N. 1992. T cell recognition of allopeptides in context of syngeneic MHC. J. Immunol. 148:35-40.
45. Liu, Z., et al. 1993. Limited usage of $\mathrm{T}$ cell receptor $\mathrm{V}$ beta genes by allopeptide-specific T cells. J. Immunol. 150:3180-3186.

46. Liu, Z., et al. 1993. Contribution of direct and indirect recognition pathways to T cell alloreactivity. J. Exp. Med. 177:1643-1650.

47. Lechler, R.I., and Batchelor, J.R. 1982. Restoration of immunogenicity to passenger cell-depleted kidney allografts by the addition of donor strain dendritic cells. J. Exp. Med. 155:31-41.

48. Chai, J.G., et al. 1999. Critical role of costimulation in the activation of naive antigen-specific TCR transgenic CD8+ T cells in vitro. J. Immunol. 163:1298-1305.

49. Warrens, A.N., Lombardi, G., and Lechler, R.I. 1994. Presentation and recognition of major and minor histocompatibility antigens. Transpl. Immunol. 2:103-107.

50. McGeer, P.L., and McGeer, E.G. 2000. Autotoxicity and Alzheimer disease. Arch. Neurol. 57:789-790.

51. Popovic, M., Caballero-Bleda, M., Puelles, L., and Popovic, N. 1998 Importance of immunological and inflammatory processes in the pathogenesis and therapy of Alzheimer's disease. Int. J. Neurosci. 95:203-236.

52. Gebicke-Haerter, P.J., Van Calker, D., Norenberg, W., and Illes, P. 1996. Molecular mechanisms of microglial activation. A. Implications for regeneration and neurodegenerative diseases. Neurochem. Int. 29:1-12.

53. Krogsgaard, M., et al. 2000. Visualization of myelin basic protein (MBP) $T$ cell epitopes in multiple sclerosis lesions using a monoclonal antibody specific for the human histocompatibility leukocyte antigen (HLA)DR2-MBP 85-99 complex. J. Exp. Med. 191:1395-1412.

54. Sorensen, T.L., et al. 1999. Expression of specific chemokines and chemokine receptors in the central nervous system of multiple sclerosis patients. J. Clin. Invest. 103:807-815.

55. Bo, L., et al. 1994. Detection of MHC class II-antigens on macrophages and microglia, but not on astrocytes and endothelia in active multiple sclerosis lesions. J. Neuroimmunol. 51:135-146. 